\title{
Enhancing Comprehension by Effectively Using Reading Strategies
}

\author{
Preeti Jaiswal ${ }^{1}$ \\ ${ }^{1}$ English Language Centre, University of Bahrain, Kingdom of Bahrain \\ Correspondence: Preeti Jaiswal, English Language Centre, University of Bahrain, Kingdom of Bahrain.
}

\author{
Received: October 6, 2018 Accepted: October 28, 2018 Online Published: November 28, 2018 \\ doi:10.5539/ells.v8n4p14 URL: https://doi.org/10.5539/ells.v8n4p14
}

\begin{abstract}
The paper examined the reading strategies used by ESL learners at University of Bahrain to comprehend academic material. It investigated the interdependence between the use of reading strategies by ESL learners' and their reading comprehension attainment. To accomplish this goal, three instruments were used: a survey of the Metacognitive Awareness of Reading Strategies Inventory (MARSI) by Mokhtari and Sheorey (2002) and a Pre-reading comprehension test and Post-reading comprehension test and a paired sample t-test. The paper used quantitative data collected from 100 students studying in the Foundation Program at the English Language Centre and Department of Applied Studies at University of Bahrain. The findings of this research showed a notably positive relationship between the use of cognitive and metacognitive reading strategies by the students and their reading comprehension achievement. The compilation of the quantitative data, displayed that students practiced Global Reading Strategies appreciably, followed subsequently by Support Reading Strategies and Problem Solving Reading Strategies.
\end{abstract}

Keywords: global reading strategies, problem solving reading strategies, support reading strategies, reading comprehension

\section{Introduction}

Reading is a receptive skill that is appraised as essential for language acquisition (Aebersold \& Field, 1997) since it fosters language development. According to Krashen (1982) reading is a comprehensible input and contributes to writing and speaking competence. The crucial importance of this skill in language competency is stimulating a remarkable increase in the number of researches being conducted on reading in academic contexts. This study adopted the perception of Snow (2002) regarding reading comprehension. According to him, reading comprehension is a process in which the reader engages with the text to construct meaning. Ismini $(2003$, p. 516$)$ suggests that reading materials are considered difficult possibly due to learners' possessing limited range of vocabulary or lacking techniques to find the gist of an academic text which hinders comprehension of the text. As reading is a multifaceted process so learners must be aware of different strategies to make predictions about what will happen next, monitor their understanding of content, sequence events, clarify confusing sections of a text, or connect what they are reading to their own experience or prior knowledge. An awareness of reading strategies helps the learners to gain knowledge from a text (Anderson, 2002; Mokhtari \& Sheorey, 2002; Oxford, 1994). Proficient readers use a variety of strategies resulting in active, intentional and self-regulated reading (Trabasso \& Bouchard, 2002) as they prepare to read, as they read and after they read in order to enhance comprehension of the text. In fact, reading comprehension strategies empower readers- to predict using visual cues, make sense of what they read and solve tasks when they encounter difficulties while comprehending any text (Block, 1986, p. 465), Taylor (2007, p. 77). This study examined the interrelationship between reading strategies usage and level of reading accomplishment among ESL students attending full-time academic study at college level. An analysis of the impact of reading strategies usage on reading competency may give indications to ESL learners on procedures to adopt for developing their English reading in academic contexts.

\section{Material Studied}

According to Paris et al. (1983, p. 293), reading strategies are skills adopted by learners in relation to specific reading contexts as well as readers' awareness, control and intention. Reading strategies are situational and are used intentionally by readers (McEwan, 2004). A strategic reader understands three sources of knowledge: declarative knowledge (what the strategies are), procedural knowledge (how to use the strategies), and conditional knowledge (when and why to use the strategies). Block (1986, p. 465) established that reading 
strategies indicate, "How readers conceive a task, what textual cues they attend to, how they make sense of what they read, and what they do when they do not understand". Hence being strategic is not a skill that can be taught by drill; it is a method of approaching reading and reading instruction. A strategic reader skillfully "coordinates individual strategies by altering, adjusting, modifying, testing and shifting tactics as is fitting, until a reading comprehension problem is solved."'(Trabasso and Bouchard, 2002, p. 186) In fact, Cogmen and Saracaloglu (2009) proclaimed that simple techniques like underlining, taking notes, or highlighting the text can assist learners in comprehending and remembering the content. The application of adequate EFL reading strategies is contemplated as a saliently contributory factor for successful language learning (Ikeda \& Takeuchi, 2006). Likewise, Oxford and Crookall (1989) evinced that SL/FL learners utilized reading strategies in fostering more efficient and effective language learning. Therefore, it is imperative, that instructional strategies should include scaffolding by teachers and opportunities for students to practice and apply strategies (Palinscar and Brown, 1984; Rosenshine et al., 1996) so that "readers eventually become adept at using their prior knowledge as they read to make predictions about what might happen next and to understand ideas as they encounter them" (Paris, Wasik, \& Turner, 1991).Mokhtari and Reichard (2000) suggested the reading strategy questionnaire called MARSI (Metacognitive Awareness of Reading Strategies Inventory) to measure learners' strategy use while reading academic materials. They prorated reading strategies into three categories: global strategies (orienting towards global analysis of the texts), problem-solving strategies (aiming at solving problems when the text becomes difficult), and support strategies (using reference materials, note-taking and other practical strategies). According to Block (1986) and Carrell (1989) Global strategies are metacognitive strategies, and such strategies are intentionally used to achieve a global analysis of the reading text such as, finding the main idea of a reading text, utilizing background knowledge, previewing the text as to its length and organization, or using typographical aids, tables, chart and other visuals to get a general idea of a reading text. On the other hand, Problem-solving strategies are essentially cognitive strategies. Sheorey and Mokhtari (2001, p. 436) propose that cognitive strategies are the actions and techniques readers use while engaging directly with the reading text. According to them, these strategies are divested, when problems arise in understanding textual information. For instance, altering the reading speed when the academic text becomes difficult or easy, surmising the meaning of unknown words, inferring from context or re-reading for improving comprehension. These strategies assist readers in tackling problems while reading and enable readers to get through the text skillfully Finally, according to Sheorey and Mokhtari (2001, p. 436), Support strategies are basically supportive actions learners take that are intended to aid the reader in comprehending the text. Examples include are using reference material or a dictionary, taking notes, highlighting the text, summarizing, underlining key words, and other practical strategies to improve reading comprehension. By employing support or functional strategies, a reader can sustain responses to the reading text. Generally, in a L2 context, it is believed that readers often use more cognitive strategies to decode the meaning of a text, due to limited linguistic knowledge; and comprehension monitoring is particularly crucial to ensure effective and efficient use of strategies (Pang, 2008).

\section{Method}

The study attempts to answer the following question: Is there a significant correlation between ESL learners reading strategy use and reading comprehension achievement?

To achieve the aim of the study, the following measures were taken. A quantitative method was used for data collection. The quantitative data instruments comprised students' questionnaire on reading skills with $100 \mathrm{ESL}$ students. The MARSI questionnaire was used to determine the usage of reading strategies. Also a reading comprehension Pre-test was used to check learners' employability of reading strategies at the beginning of the experiment. A posttest reading comprehension test was conducted to find out learners' perceived use of reading strategies. Finally, a paired sample t-test was used to find out if there was interdependence between using strategies and reading accomplishment.

\subsection{Data Collection and Data Analysis}

\subsubsection{MARSI Questionnaire}

The instrument used in this study is the MARSI questionnaire and a reading comprehension test, designed by the researcher, to measure the perceived use of reading strategies while reading academic materials. MARSI questionnaire consists of 30 questions and is answered according to a 5-point Likert scale which ranged from numbers one to five. 1 signifies "never" or "almost never" ,2 expresses "only occasionally" ,3 indicates "sometimes", 4 stands for "usually" and 5 means "always" or "almost always." The thirty reading strategies are divided into three divisions: global strategies include 13 items, while 8 items are linked with problem-solving strategies and 9 items identify with support strategies. The lowest and highest scoring range for overall reading 
strategies are 30 and 150, respectively. As regards each sub-category, the maximum and minimum possible scores for global strategies are between 13-65 and for problem solving strategies they range from 8-40 and for support reading strategies they can vary from 9-45, respectively. This questionnaire was used to determine the extent of respondents' awareness of comprehension strategies when reading academic materials.

A higher score indicates a higher usage of the reading strategies and vice versa (Mokhtari \& Sheorey, 2002). After collecting the quantitative data, the attached reading strategies inventory rubric has been used to analyze the raw data and get the mean of each strategy. The final average of SORS and reading comprehension test represents how frequently students used the thirty reading strategies when comprehending academic reading materials. The average for each item of the survey was also obtained to ascertain which tier of strategies (i.e., global, problem-solving, or support strategies) students were inclined towards when reading and if it boosted their reading achievements.

\subsubsection{Reading Comprehension Test}

Similarly, by applying paired sample t-test to the result of the reading comprehension test the correlation between reading strategy usage and reading competency has been determined. To ensure the validity of the reading comprehension test, it was initially showed to experts in the field of ELT and Linguistics in the Department of English Language and Literature, Faculty of Arts, University of Bahrain. The Pretest and Posttest used to test reading comprehension comprised of three sections which comprehensively measured the three reading strategies namely global strategies, problem-solving strategies and support strategies. The first section measured the students' ability to find the main idea, find meaning of vocabulary in context, identify pronoun references, and answer factual questions by previewing, skimming, scanning and reading in details. The next section examined the students' ability to read charts and answer related questions, the final section explored the students' ability to make inferences, summarize, find similarities, distinguish between facts and opinion, determine main idea and supporting details There were 15 test items and the total marks was 30.

\section{Result}

The quantitative data collected from the students were computed, analyzed, and interpreted with statistical figures. Scores of the 100 respondents were recorded according to reading comprehension categories namely the Global Reading Strategies (GLOB), Problem Solving Strategies (PROB) and Support Strategies (SUPP) and totaled to achieve the complete score for all respondents. The statistical procedures used to analyze data in this study were mean scores and also frequency and percentage. The descriptive statistics of frequency and the percentage were used to ascertain the level of awareness of the comprehension strategies among the ESL students whereas; the mean scores were used to find out the how frequently reading strategies were used by the respondents.

The overall mean for the strategies is graded below:

High range has (mean of 3.5 or higher)

Moderate range has (mean of 2.5 to 3.4 )

Low range has (mean of 2.4 or lower)

\subsection{Result-Cognizance of Reading Strategies Used}

4.1.1 Means and standard deviations for a Survey of Reading Strategies

Table 1. Category: Global Reading Strategies (GLOB)

\begin{tabular}{llll}
\hline Item No. & Description of Items /Strategies & M & 4.72 \\
\hline 1 & I have a purpose in mind when I read & 3.24 & .47 \\
3 & I think about what I know to help me understand what I read & .55 \\
4 & I preview the text to see what it is about before reading it. & 3.01 \\
7 & I think about whether the content of the text fits my reading purpose & .46 \\
10 & I skim the text first by noting characteristics like length and organization. & .26 \\
14 & I decide what to read closely and what to ignore. & 3.73 \\
17 & I use tables, figures and pictures in text to increase my understanding & 3.71 \\
19 & I use context clues to help me better understand what I am reading & 3.45 \\
22 & I use typographical features like bold face and italics to identify key information & 3.04 & .42 \\
23 & I critically analyze and evaluate the information presented in the text & 3.26 \\
25 & I check my understanding when I come across new information & .51 \\
26 & I try to guess what the material is about when I read & .24 \\
29 & I check to see if my guesses about the text are right or wrong & .51 \\
\hline
\end{tabular}


The quantitative data, consisting of mean and standard deviation, in the survey of Global Reading Strategies usage, in table 1 suggests that seventy two (72\%) students had high mean score in using Global Reading strategies while twenty eight (28\%) students used these strategies in mediocre level. The suggests that majority of students can apply reading comprehension strategies such as finding the main idea of a reading text, skimming text, previewing the text by using text structure and textual features to predict the content of the text.

Table 2. Category: Problem Solving Reading Strategies (PROB)

\begin{tabular}{|c|c|c|c|}
\hline Item No. & Description of Items /Strategies & M & SD \\
\hline 8 & I read slowly and carefully to make sure I understand what I am reading & 4.6 & .49 \\
\hline 11 & I try to get back on track when I lose concentration & 3.8 & .44 \\
\hline 13. & I adjust my reading speed according to what I am reading. & 3.83 & .37 \\
\hline 13 & I adjust my reading speed according to what I'm reading. & & \\
\hline 16 & When text becomes difficult, I pay closer attention to what I am reading. & 3.85 & .35 \\
\hline 18 & I stop from time to time and think about what I'm reading. & 2.85 & .74 \\
\hline 21 & I try to picture or visualize information to help remember what I read. & 2.85 & .90 \\
\hline 27 & When text becomes difficult, I reread it to increase my understanding & 3.01 & .81 \\
\hline 30 & When I read, I guess the meaning of unknown words or phrases & 3.44 & .49 \\
\hline
\end{tabular}

According to the data for Problem Solving Strategies (PROB) in table 2, fifty (50\%) students used these strategies in high-level while fifty $(50 \%)$ students used these strategies in mediocre-level. This indicates that these strategies, which essentially focus on solving problems when the reading test becomes difficult like paying attention to reading, adjusting reading rate, reading slowly and guessing the meaning of unknown words are used by students moderately.

Table 3. Category: Support Reading Strategies (SUPP)

\begin{tabular}{|c|c|c|c|}
\hline Item No. & Description of Items /Strategies & $\mathrm{M}$ & $\mathrm{SD}$ \\
\hline 2 & I take notes while reading to help me understand what I read & 4.67 & .51 \\
\hline 5 & When text becomes difficult, I read aloud to help me understand what I read & 2.8 & .55 \\
\hline 6 & I summarize what I read to reflect on important information in the text. & 2.51 & .50 \\
\hline 9 & I discuss what I read with others to check my understanding. & 4.63 & .52 \\
\hline 12 & I underline or circle information in the text to help me remember it. & 4.69 & .45 \\
\hline 15 & I use reference materials (e.g., a dictionary) to help me understand when I read & 3.76 & .45 \\
\hline 20 & I paraphrase (restate ideas in my own words) of better understand what I read & 251 & .50 \\
\hline 24 & I go back and forth in the text to find relationships among ideas in it & 4.18 & .41 \\
\hline 28 & I ask myself questions I like to have answered in the text & 2.53 & .50 \\
\hline
\end{tabular}

The data for Support Reading Strategies (SUPP) in table 3 presents forty-four students (44\%) use these strategies in high level whereas $66 \%$ used these strategies in mediocre-level. This manifests that more than average number of students use functional or support strategies such as using the dictionary, involving outside reference materials, underlining or circling information and other practical strategies to fostering their reading achievement.

Table 4. Analysis of Each Category of the Survey of Reading Strategies

\begin{tabular}{llll}
\hline Category & Item numbers & Mean & Standard Deviation \\
\hline Global Reading Strategies (GLOB) & $1,3,4,7,10,14.17,19,22,23,25,26,29$ & 3.67 & .61 \\
Problem Solving Reading Strategies (PROB) & $8,11.13,16,18,21,27,30$ & 3.52 & .57 \\
Support Reading Strategies (SUPP) & $2,5,6,9,12.15,20,24,28$ & 3.54 & .99 \\
All reading strategies & & 3.57 & .23 \\
\hline
\end{tabular}

Table 4 shows the average of the qualitative data. An analysis of the survey of reading strategies (SORS) exhibits that the average mean of Global strategy is 3.67.From the survey result, it can be inferred that students use all 13 reading strategies for comprehension of reading texts. As regards, Problem Solving strategies, the average mean is 3.52 which shows that students do use the techniques to engage with the text and improve reading achievement. The average mean for the Support Strategies is 3.54 which also indicate that students use these functional reading strategies to enhance comprehension. An analysis of the findings reveals that 16 
strategies were used highly-frequently, while 14 strategies were used in moderate-frequency category. However there were no reading strategies that were used in low-frequency range. The most frequently used reading strategy was the global strategy (M 3.67), I have a purpose in mind when I read $(\mathrm{M}=4.72)$; followed by another global strategy, I preview the text to see what's it about before reading it $(\mathrm{M}=4.7)$ and the third most frequently used strategy was the support strategy, I underline or circle information in the text to help me remember it $(\mathrm{M}=4.69)$.

Overall students used all the 30 reading strategies while reading. The results of the study reveal that the average for individual strategy items ranged from 4.72 to 2.51 , which classifies into high and moderate level.

\subsubsection{The Effectiveness of Reading Strategies Used}

As the aim of this study was to measure how students' levels of awareness and usage of reading comprehension skills improved their proficiency in reading academic text, so for this purpose, a Pretest and Posttest reading comprehension test was given to students, to gauge their level of comprehension. According to the paired sample $\mathrm{t}$-test, the results showed that there was a significant difference, $\mathrm{t}(99)=35.74, \mathrm{p}<0.05$. The mean for pretest was $63.4 \%$.( SD 1.6) and the mean for posttest was 70.2\% (SD 3.3). The data of reading strategy usage by students and their reading competency, based on the Pretest and Posttest reading comprehension test, indicated that a perception of the strategies benefitted the students, as they practiced these reading strategies, to enhance their understanding and interpretation of reading texts and showed remarkable improvement.

\section{Discussion}

Reading comprehension is a process that is learned over time with much practice. Hence instructors must provide opportunities for ample practice using a variety of texts as well as directly modelling strategies step-by-step. One way to organize teaching reading strategies, is to classify them into before reading, during reading, and after reading stages. Before Reading Strategies would incorporate previewing headings, sub heading and captions, surveying accompanying pictures, making predictions regarding the text, etc. Simply telling before-reading strategies independently, without direct and explicit instruction, will not enable students to internalize the process. Teacher could generate questions on the main idea and encourage students to activate prior knowledge related to topic, connecting it to previous texts and real world experiences and encouraging them to participate in a discussion. This would enable students to engage with the text, as well as draw connections between what they are reading and their schema and life experiences. It would give them a purpose for reading and make them think actively as they read. This motivation would enhance comprehension. During Reading Strategies entail strategies that students use while they are reading a selected text. These include paraphrasing, elaborating, comparing what is being read to what is already known, changing reading rate, rereading, etc. Usually, authors do not always provide complete information on a given topic. Students need to use context clues to "read between the lines." These strategies help students understand during reading texts. Teachers could engage students in monitoring their comprehension so that they automatically learn to look for the intended meaning of a text. This would make them strategic readers who can use context clues to grasp meaning, identify new information and explain similarities and differences between new information in the text with what they previously learnt. After-Reading Strategies include strategies that students use after they have completed reading a text. These strategies comprise of summarizing, making inferences and drawing conclusions regarding author's message and assist students in confirming predictions made before reading and reflecting on the author's message in the text. Extensive practice empowers students to use a combination of strategies before, during, and after a preliminary reading of an academic text and they eventually develop into strategic readers who can comprehend diverse texts fluently.

\section{Conclusion}

This study concludes that that there is a consequentially positive relationship between the use of overall cognitive and metacognitive reading strategies by the participants and their reading comprehension achievement. The statistics reveal a remarkable improvement in respondents' reading abilities. Hence, multiple modeling of strategies by instructors in reading contexts will boost learners' cognizance of reading strategies and encourage learners to become effective readers, who can apply these comprehension strategies to get meaning from a variety of academic materials. According to the findings it can be concluded that students were inclined to use Global Reading Strategies most, succeeded by Problem Reading Strategies and eventually Support Reading Strategies. Barnett (1988) stated that the proficient readers showed more awareness of their use of metacognitive reading strategies in reading comprehension compared to the less proficient readers. Chern (1993) also affirmed that there is a favorable association between readers' metacognitive reading strategy awareness and their reading comprehension processes in EFL/ESL. 


\section{Limitations and Recommendation}

This study is limited by the relatively small sample size used for proficiency as 100 students studying the Foundation Program at the English Language Centre and Department of Applied Studies during the academic year 2017-18 at University of Bahrain, participated in this study.

Based on the findings, this study recommends, students should be given a lot of practice and explicit guidance in effective usage of reading strategies. A further research on awareness and employability of reading strategies, especially in the ESL context, can be conducted by comparing students from different faculties in University of Bahrain. Also, it would be interesting to find out if there is a significant difference between higher-proficiency readers and lower-proficiency readers in connection with their usage of cognitive and metacognitive reading strategies. It is recommendable, at a later stage, to research the progress of students who participated in this study, to attain a clearer perception into their ongoing progression in using strategies skillfully and to which extend, do their utilization, boost their reading comprehensibility as they progress to higher levels of education. A reflection of these determinants can be valuable for future researches on reading strategies.

\section{Acknowledgements}

I am grateful to the distinguished faculty members in the Department of English Language and Literature, Faculty of Arts, University of Bahrain who took out time to review my Reading Comprehension test before it was used for this study.

\section{References}

Aebersold, J., \& Field, M. (1997). From Reader to Reading Teacher: Issues and Strategies for Second Language Classrooms. Cambridge: Cambridge University Press.

Anderson, N. J. (2002). The Role of Metacognition in Second/Foreign Language Teaching and Learning. ERIC Digest. Washington DC: ERIC Clearinghouse on Languages and Linguistics.

Barnett, M. A. (1988). Reading through Context: How Real and Perceived Strategies Use Affects L2 Comprehension. Modern Language Journal, 72, 150-162.

Block, E. L. (1986). The Comprehension Strategies of Second Language Readers. TESOL Quarterly, 20(3), 463-494. https://doi.org/10.2307/3586295

Carrell, P. L. (1988). Some causes of text-boundedness and schema interference in ESL reading. In P. L. Carrell, J. Devine, \& D. E. Eskey (Eds.), Interactive Approaches to Second Language Reading. Cambridge: Cambridge University Press.

Carrell, P. L. (1989). Metacognitive Awareness and Second Language Reading. The Modern Language Journal 73(2), 121-134. https://doi.org/10.1111/j.1540-4781.1989.tb02534.x

Chern, C. L. (1993). Chinese Students' Word-Solving Strategies in Reading in English. In T. Huckin, M. Haynes, \& C. Coady (Eds.), Second Language Reading and Vocabulary Learning (pp. 67-85). Norwood, NJ: Ablex.

Cogmen, S., \& Saracaloglu, A. S. (2009). Students' usage of reading strategies in the faculty of education. Procedia Social and Behavioral Sciences, 1, 248-251.

Ikeda, M., \& Takeuchi, O. (2006). Clarifying the differences in learning EFL reading strategies: An analysis of portfolios. System, 34, 384-398.

Ismini, R. (2003). The Effectiveness of Reading Strategy Training in Developing Students' Reading Ability. Elementary School Journal, 92(5), 513-555.

Krashen, S. (1982). Principles and Practice in Second Language Acquisition. New York: Pergamon.

Mokhtari, K., \& Reichard, C. (2002). Assessing students' metacognitive awareness of reading strategies. Journal of Educational Psychology, 94(2), 249-259.

Mokhtari, K., \& Sheorey, R. (2002). Measuring ESL students' awareness of reading strategies. Journal of Developmental Education, 25, 2-10.

O’Malley, J., \& Chamot, A. (1990). Leaning Strategies in Second Language Acquisition. Cambridge: Cambridge University Press.

Oczkus, L. (2003). Reciprocal teaching at work: strategies for improving reading comprehension. Newark, DE: International Reading Association. 
Oxford, R. L. (1990). Language learning strategies: What every teacher should know. Boston, MA: Heinle \& Heinle.

Oxford, R., \& Crookall, D. (1989). Research on language learning strategies; methods, findings, and instructional issues. The Modern Language Journal, 73(4), 103-114.

Palincsar, A. S., \& Brown, A. (1984). Reciprocal teaching of comprehension fostering and comprehension-monitoring activities. Cognition and Instruction, 1, 117-175.

Pang, J. (2008). Research on good and poor reader characteristics: Implications for L2 reading research in China. Reading in a Foreign Language, 20(1), 1-18.

Paris, S. G., Lipson, M. Y., \& Wixson, K. K. (1983). Becoming a Strategic Reader. Contemporary Educational Psychology, 8, 293-316.

Sheorey, R., \& Mokhtari, K. (2001). Differences in the metacognitive awareness of reading strategies among native and non-native readers. System, 29, 431-449.

Snow, C. E. (2003). Assessment of reading comprehension: Researchers and practitioners helping themselves and each other. In A. P. Sweet \& C. Snow (Eds.), Rethinking Reading Comprehension (pp. 192-206). New York: Guilford.

\section{Copyrights}

Copyright for this article is retained by the author, with first publication rights granted to the journal.

This is an open-access article distributed under the terms and conditions of the Creative Commons Attribution license (http://creativecommons.org/licenses/by/4.0/). 